\title{
Ort Wo sollen wir hingehen die ganze Zeit?
}

$\mathbf{R}$ und 200 Jahre nach Immanuel Kant kommt durch die Frage zu den eigentlich alle subsumierenden kantischen Fragen hinzu:»Wo sollen wir hingehen die ganze Zeit?«Der Mensch scheint einen innewohnenden Drang nach Ortswechseln zu verspüren. "Sollen wir nicht noch irgendwo hingehen?« ist eine oft gestellte Frage. Warum nicht einfach mal bleiben? Nein, er ist ruhelos, der Mensch. Er geht zur Schule, geht zur Arbeit, geht einkaufen, geht fremd, geht spazieren, geht aus, geht Kaffee trinken, geht Zigaretten holen, geht verloren. Er plant Urlaub, bekommt Heimweh, plant wieder Urlaub, geht wandern und bekommt Blasen, weil er absurderweise bei der ganzen Geherei am wenigsten auf seine Füße achtet, da diese ja auch so weit weg sind von der ganzen ortssüchtigen Aufmerksamkeit. Aber wo sollen wir eigentlich hingehen die ganze Zeit? Kommt man an, will man auch schon wieder weg. Liegt es vielleicht an der von Kant diagnostizierten nur zufälligen Örtlichkeit der Seele, die also ständig auf der Suche ist? Haben wir Angst zu enden wie Oblomow auf der Couch? Oder verspüren wir diese Sehnsucht nach Ortswechseln gerade weil wir die ganze Zeit an ein- und demselben Ort, nämlich in uns selbst, als dem »absoluten Subjekt«, gefangen sind? 